\title{
Adsorption of Acetic Acid, Cadmium ions, Lead ions and Iodine Using Activated Carbon from Waste Wood and Rice Husks
}

\author{
GOODHEAD, T O; DAGDE, K K
}

\author{
Department of Chemical/Petrochemical Engineering, Rivers State university of Science and Technology \\ Port Harcourt, Nigeria
}

\begin{abstract}
This paper presents the performance evaluation of locally prepared activated carbon from rice husk and saw dust. The raw materials were carbonized at different temperatures $\left(600-800^{\circ} \mathrm{C}\right)$ using sodium hydroxide $(\mathrm{NaOH})$ as the activating agent. The study includes moisture content determination of the raw materials used in the activation and carbonization processes. The effects of variations in carbonization temperature and concentration of activating agent on various performance indices for good quality absorbent were investigated. The percentage yield of the activated carbon from the raw materials as well as iodine number and adsorption of heavy metals from aqueous solutions were also determined. The experimental data which make a comparative assessment of activated carbon obtained from rice husk and saw dust were also presented. Preliminary examination of the raw materials showed that rice husk and saw dust had a moisture content of $14.6 \%$ and $5.8 \%$ respectively. Increase in carbonization temperature decreases yield of the active carbon. The highest yield of about $48 \%$ was obtained from rice husk at $600{ }^{\circ} \mathrm{C}$, with moisture content of $26 \%$. The rice husk at $800^{\circ} \mathrm{C}$ gave a yield of $47.2 \%$ with moisture content of $26.5 \%$. Whilst the yield of the saw dust was $44 \%$ at $600^{\circ} \mathrm{C}$ and $40 \%$ at $800^{\circ} \mathrm{C}$ with moisture content of $17 \%$ and $19 \%$ respectively. A detailed study of mass transfer processes indicated that activated carbon from these materials show good performance. @JASEM
\end{abstract}

With the situation of the Nigerian economy and the population increase, the need has come for self sufficiency to achieve a stable and comfortable economy. A research on our waste materials can yield useful adsorbents, which have numerous uses and applications in our various industries land application of these materials may improve crop production. However, this practice can also degrade the environment with the introduction of potentially harmful substances such as traces of heavy metals into the soil.

Heavy metals have been applied to soil with pesticides, as plant nutrients and as a constituent of waste products. These heavy metals may include cadmium, zinc, lead etc. Thus taking into account the harmful effect of these heavy metals, it was considered of great extent to study the adsorption process of these metals from aqueous solution using locally prepared activated carbon which can be produced from wide variety of these carbon rich raw materials.

Over the decades there has been rapid population expansion and technological development in Nigeria. This leads to a more extensive and intensive use of available supplies of water, and ultimately to the pollution and degradation of the quality of these waters. Pollution is inevitable because domestic and industrial activities generate wastes, which are discharged into the environment. These wastes or effluent might contain non-biodegradable matter, toxic heavy metals, organic matter and also might give off some offensive odour (Webber and Vernana,
1967, Eckenfelder, 2000, Tchobanoglous et' al., 2003.). These can cause negative impact on the people living around those areas. Activated carbon is thus used as an effective adsorbent for the removal of these dissolved organic substances, heavy metals, obnoxious odour and colour from water and waste waters. Recent researchers studied the use of chemically modified and unmodified cassava waste for the removal of $\mathrm{Cd}, \mathrm{Cu}$, and $\mathrm{Zn}$ ions from solution (Abia et al., 2003). While sorption of $\mathrm{Cd}, \mathrm{Cu}$, and $\mathrm{Zn}$ ions from aqueous solutions by cassava wastes biomass was investigated by Horsfall et al., 2004.

Recent reports indicate an escalating demand for and use of imported adsorbent on the developing countries, particularly Nigeria (Olafe and Bosch, 1996, Nwokoma and Anane, 2010, Okafor and Aneke, 2006, Emmanuel and Innocent, 2008). Thus in 1987, activated carbon worth $\$ 1,670,117$ was imported from USA, Europe and Kuwait. In 1999, $\$ 5,096,999$ worth of imports were made with brazil, China, and Taiwan (also developing countries) providing $98.9 \%$ of these imports, while the remainder was supplied by USA (Olafe and Bosch, 1996). Governments of these developing countries (Nigeria inclusive) are concerned with the amount of foreign exchange spent on importing these adsorbents, thus local substitutes are given some consideration. Amongst various substitutes considered, activated carbon has shown much potential. This is due to its versatilities and abundance of carbonaceous agricultural wastes. 
Despite the work done so far, there still remains according to recent reports a dearth of rigorous and comprehensive chemical engineering information published on the process development of activated carbon sourced from these raw materials particularly palm kernel shells, animal bones, rice husks and saw dust (Balci and Dogu, 1992).

The aim of this research is to determine the performance of activated carbon derived from rice husk and saw dust in the removal of heavy metals from aqueous solution of known concentration of the metal salts. And also to provide additional information relating to the process development of activated carbon from rice husks and saw dust using chemical activation method.

\section{MATERIALS AND METHODS}

Materials: The saw dust was collected from a saw mill which was close enough for research. It was obtained from a variety of woods which include chanomi, obeche, mahogany and iroko. . The rice husk was obtained from local rice farmers which appeared in its normal oblong shape. Other materials for the experiment include chloroform, ethanol, sodium hydroxide, phosphoric acid, acetic acid, iodine solution, sodium thiosulphate, cadmium and lead nitrates, indicator (Phenolphthalein and xylenol orange), sulphuric acid, hexamine, ethylene ditetra acetate solution (EDTA), ammonia solution, potassium cyanide, and sodium sulphide solution, $\mathrm{pH}$ meter.

EXPERIMENTAL PROCEDURE: 2000g of each powdered sample (rice husk and saw dust) were mixed with $1500 \mathrm{ml}$ of $50 \% \mathrm{NaOH}$ solution into a plastic bucket containing the powdered sample until a semi-fine paste was formed. The mixture was allowed to remain in the bucket for a minimum of 12 hours before using it for further experiment. This impregnation process was carried out batch by batch for each required temperature $\left(600^{\circ} \mathrm{C}\right.$ and $\left.800^{\circ} \mathrm{C}\right)$ for rice husk and saw dust. The paste obtained from the process of impregnation was sent immediately for carbonization. The paste was carbonised using furnace equipped with temperature control device.
Each furnace crucible was pre-weighted before filling up with respective known weight of each paste and put inside the furnace. The timing of the carbonization was taken when the temperature of the furnace had reached the specific temperature $\left(600^{\circ} \mathrm{C}\right.$ and $800^{\circ} \mathrm{C}$ ), with the aid of the thermostat control knob. This temperature was maintained for a period $3 \frac{1}{2}$ hours before it was switched off and allowed to cool down to room temperature. The crucible and the product were weighed together while the difference between the crucible plus product weight and the weight of the crucible gave the weight of product. Each product was thoroughly washed with water several times before neutralizing with $50 \% \quad \mathrm{H}_{3} \mathrm{PO}_{4}$ solution under a $\mathrm{pH}$ meter at a $\mathrm{pH}$ value of 7.0. The neutralized product was also washed again to remove the resulting salt of sodium phosphate due to the neutralization. The samples were then filtered and dried, and thereafter crushed to its powdered form. The following properties of the activated carbon from the rice husk and saw dust at the respective temperatures were also determined using ASTM standards and chemical engineering handbook (Perry et al., 1987, Babu and Ramakrishna, 2001).

\section{RESULTS AND DISCUSSION}

Figure 1 shows the effect of temperature on the adsorptive capacity of activated carbon obtained from rice husk $(\mathrm{RH})$ and saw dust (SD). The adsorptive capacity of the four samples shows a peculiar trend in acetic acid solution. RH $600^{\circ} \mathrm{C}>\mathrm{SD} 600^{\circ} \mathrm{C}>\mathrm{RH}$ $800^{\circ} \mathrm{C}>\mathrm{SD} 800^{\circ} \mathrm{C}$. This demonstrates the extend of the pore surface developed within the matrix of the activated carbon. Using the principle that, the greater the surface area, the higher the number of adsorptive site available. The results show that $\mathrm{RH} 600^{\circ} \mathrm{C}$, having the highest adsorptive capacity, will have the most developed surface area.

The results of the experiment are presented using $\log / \log$ plots. The graph shows that the adsorptive capacities of the samples increase with increase in initial concentration of acetic acid with the exception of sample 2 ( $\mathrm{RH} 800^{\circ} \mathrm{C}$ ) which has almost equal adsorptive capacity with increase in initial concentration. 


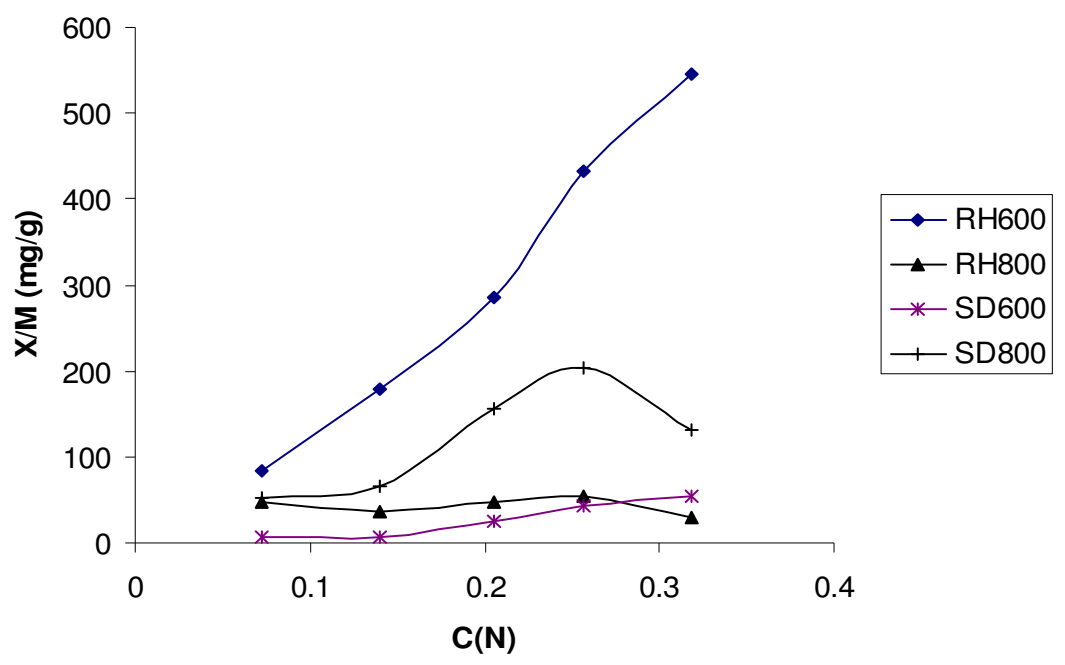

Fig.1: Acetic acid adsorbance isotherm on activated carbon

Sample RH $600^{\circ} \mathrm{C}$ has better adsorptive capacity than $\mathrm{RH} 800^{\circ} \mathrm{C}$ at the respective concentrations, while the reverse is the case with activated carbon obtained from saw dust (SD). It can be conclusively stated that lower carbonization temperature increase the adsorptive capacity of activated carbon obtained from rice husk while higher carbonization temperature favours adsorptive capacity of activated carbon from saw dust.

Figure 2 shows the effect of temperature and concentration on the iodine number of activated carbon. Iodine number is a measure of the porosity (especially within the microspores) of activated carbon and is also the amount of iodine adsorbed (mg/g).

It also shows the effect of concentration on the quantity of iodine adsorbed on activated carbon produced from rice husk and saw dust. The iodine number is the quantity of iodine adsorbed $(\mathrm{X} / \mathrm{M})$ at a residual iodine concentrations (c) of $0.02 \mathrm{~N}$. From figure 2 the iodine numbers of the various activated carbon samples were obtained as $60,1780,1650$, and 1600 for $\mathrm{RH} 600^{\circ} \mathrm{C}, \quad \mathrm{RH} 800^{\circ} \mathrm{C}, \quad \mathrm{SD} 600^{\circ} \mathrm{C}$, and $\mathrm{SD} 800^{\circ} \mathrm{C}$ respectively.

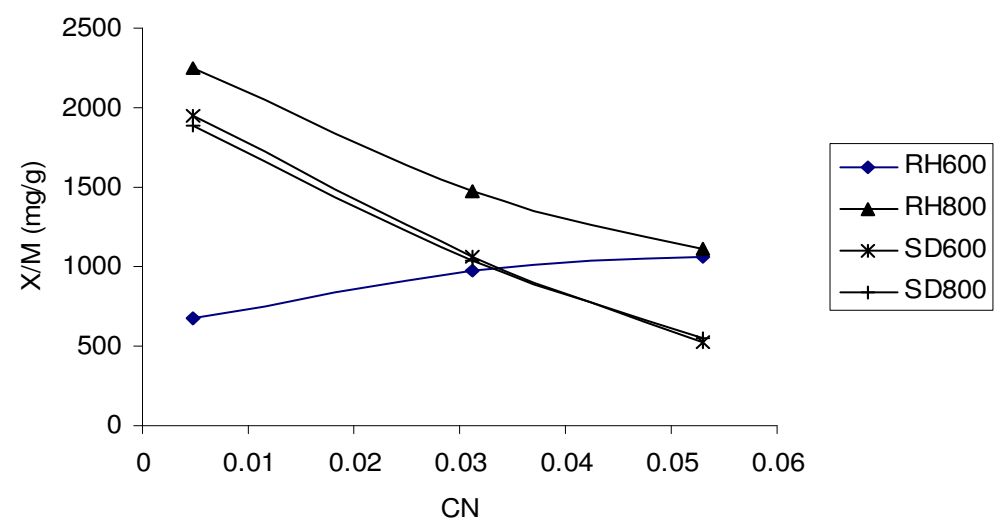

Figure 2: Iodine number determination

There is considerable difference in iodine number between the activated carbon obtained from rice husk at the difference temperatures. But this is not the case for sample obtained from saw dust. However, it is noticeable that increase in carbonization temperature increases the porosity of the carbon. This is evident from the increase in iodine number for 
the samples (rice husk and saw dust) activated at $600^{\circ} \mathrm{C}$ and $800^{\circ} \mathrm{C}$.

It can also be noted that RH samples have a better developed pore structure than the SD samples at the respective temperatures (great difference in iodine number). The iodine number for the $\mathrm{RH}$ is satisfactory compared with the commercial activated carbon. The saw dust samples were still developing, thus the need for higher carbonization temperatures.

Figures 3 and 4 shows the effect of concentration on the adsorption of lead and cadmium from aqueous solution. It is seen that there is considerable adsorption of cadmium from its aqueous solution with RH600 showing better performance than
RH800. The plot of sample SD 800 demonstrated some degree of adsorption but not up to the acceptable limit. This could be attributed to the fact that the pore surface area and pore structure were not fully developed. Thus comparing the performance of the samples, it is clearly seen that RH600 > RH800 > SD800 > SD600.

The same scenario was observed with lead from aqueous solution. However, the adsorption of cadmium from aqueous solution is better than lead. Saw dust activated at $800^{\circ} \mathrm{C}$ showed better adsorption of lead than saw dust at $600^{\circ} \mathrm{C}$. Whilst for rice husk samples, it is seen that adsorption increases with increase in initial concentration of lead samples.

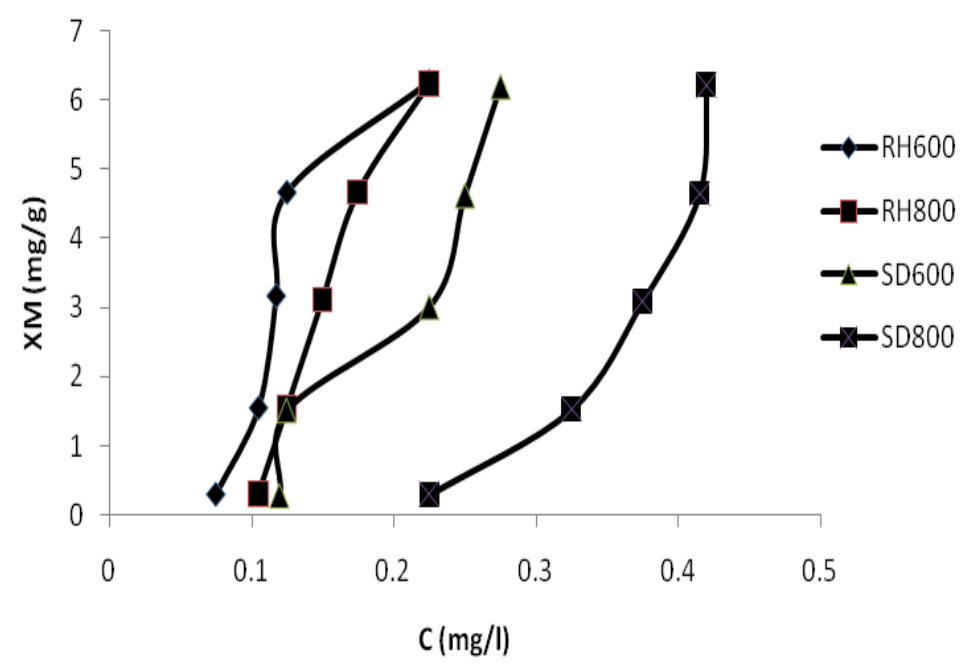

Figure 3: Adsorbance of lead (II) ion from aqueous solution

Table 1: Moisture content of the Activated Carbon at different Temperatures
\begin{tabular}{|l|c|c|c|c|}
\hline & RH 600 & RH 800 & SD 600 & SD 800 \\
\hline Weight of crucible $(\mathrm{g})$ & 96.29 & 91.08 & 90.33 & 94.81 \\
\hline Weight of sample $(\mathrm{g})$ & 1.00 & 2.00 & 2.00 & 2.00 \\
\hline Total weight $(\mathrm{g})$ & 97.29 & 93.08 & 92.33 & 96.81 \\
\hline Total weight after heating (g) & 97.03 & 92.55 & 91.99 & 96.43 \\
\hline Moisture content (\%) & $26 \%$ & $26.5 \%$ & $17 \%$ & $19 \%$ \\
\hline
\end{tabular}

The moisture content of the raw materials (rice husk and saw dust) were $14.6 \%$ and $5.8 \%$ respectively. Whilst the moisture content of the produced samples were $26 \%$ (RH 600), 26.5\% (RH 800), 17\% (SD 600) and $19 \%$ (SD 800).

The moisture (Table 1) content of the active carbon is a measure of the hydrophilic tendencies of carbon samples and this is related to the surface properties of the carbon. Thus samples with increase moisture content have better developed pore structure and internal surface area.

The yields of the various samples carbonized are presented in Table 2. It can be discerned that the yields of the two different raw materials at the respective temperatures fell within the same range with rice husk samples having the higher yield.

\section{GOODHEAD, T O; DAGDE, K K}


Adsorption of Acetic Acid, Cadmium ions, Lead ions and Iodine

Table 2: Yield of the Activated Carbon after Carbonization of Raw Material at different Temperatures

\begin{tabular}{|l|c|c|c|c|}
\hline & RH 600 & RH 800 & SD 600 & SD 800 \\
\hline Initial weight (g) & 250 & 250 & 250 & 250 \\
\hline Weight obtained (g) & 120 & 118 & 110 & 100 \\
\hline Yield (\%) & 48 & 47.2 & 44 & 40 \\
\hline
\end{tabular}

This might be due to presence of more organic components and impurities on the saw dust since the impurities are burnt off during carbonization. Since rice husk had higher yield it means that rice husk had a lower burnt off than that of saw dust. Yield for rice husk was $48 \%$ for $\mathrm{RH} 600^{\circ} \mathrm{C}$, which is higher than that of saw dust which was $44 \%$ for $\mathrm{SD} 600^{\circ} \mathrm{C}$.

It was further observed that the activated carbon obtained using rice husk as raw material was black and that obtained using saw dust as starting material was greyish. Though the rice husk carbon was black, it had some shades of black different from that of commercial grades. This clearly explains that the rice husk has higher carbon content.

Preliminary examination of the raw materials showed that rice husk and saw dust had a moisture content of $14.6 \%$ and $5.8 \%$ respectively. Increase in carbonization temperature decreases yield of the active carbon. The highest yield of about $48 \%$ was obtained from $\mathrm{RH}$ at $600^{\circ} \mathrm{C}$, with moisture content of $26 \%$. The rice husk at $800^{\circ} \mathrm{C}$ gave a yield of $47.2 \%$ with moisture content of $26.5 \%$. Whilst the yield of the saw dust was $44 \%$ at $600^{\circ} \mathrm{C}$ and $40 \%$ at $800^{\circ} \mathrm{C}$ with moisture content of $17 \%$ and $19 \%$ respectively.

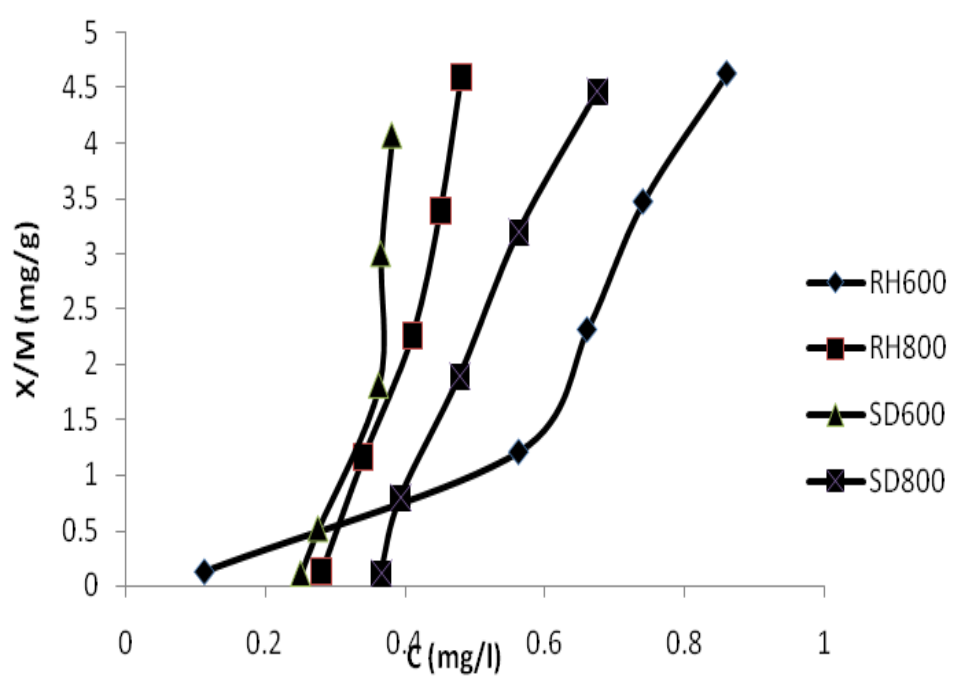

Figure 4: Adsorbance of cadmium (II) ion from aqueous solution

Saw dust sample had lower adsorptive capacity and iodine number than rice husk samples. The RH600 showed the highest absorptive capacity. From the performance test carried out, it was sedn that the rice husk samples showed better performance in the adsorption of heavy metals (cadmium and lead). Taking the samples individually, and comparing their performance it can be stated that RH600 > RH800 > SD800. It can be concluded that the saw dust samples were still in the stage of development and their carbonization temperature requirement would be greater than $800^{\circ} \mathrm{C}$. Their porous structure were not fully developed. This is obvious from the results of the iodine number. Hence carbonization of these waste materials do not only manage the environment but is also a means of providing cheaper raw material for our growing chemical and allied industries.

\section{ACKNOWLEDGEMENTS}

It is with profound gratitude we expressed our sincere appreciation to the Department of Chemical/Petrochemical Engineering, Rivers State university of Science and Technology, Port Harcourt, for providing the necessary assistance for this research work. Special thanks also go to Professor M.F.N. Abowei and his collaborators for their support during the course of the research work. 


\section{REFERENCES}

Abia A. A. Horsfall N Jr. and Didi O. (2003); The use of chemically modified and unmodified cassava waste for the removal of $\mathrm{Cd}, \mathrm{Cu}, \mathrm{Zn}$ ions from solution. Bioresource Technology vol. 90, issue 3,pp345-348.

Balci, S.: Dogu, T. Yucel, H. (1992) Characterization of Activated Carbon produced from Almond shell and Hazel nut, chem tech. Biotechno. 13:67-75.

Babu, B. V. and Ramakrishna, V. (2001) Novel Adsorbent for Solid-Liquid Separation, Proceedingof Seminar and Intensive Course (SIC-2001) on Novel Seperation Techniques and their Applications to Indian Industries, BITS Pilana, pp1-7.

Coulson, J.M. Richardson, J.F. (1998). Particle technology and separation processes, $4^{\text {th }}$ edition, volume 2: 745, 753-766.

Eckenfilder, W., W. (2000) Industrial Water Pollution Control, $3^{\text {rd }}$ Edition,McGraw-Hill Intertional Editions, Newyork, pp 417-449.

Emmanuel,O. A.,Innocent, O. O. (2008) A Comparative Study of Iron 11ions removed by Granulated Activated Carbon from Animal Horns, Journal of the Nigerian Society of Chemical Engineers, vol.23, no. 1\&2,pp 94-101.

Gorgis, B.S., Khalil, L.B. (1994). Activated Carbon from Sugar Cane Bagasse by Carbonization in the Presence of an inorganic acid. Chem tech. biotechnol, 14:15-22.

Horsfall M. Jr. Abia A. A. (2003); Sorption of Cd(ii) and $\mathrm{Zn}$ (ii) ions from aqueous solutions by cassava waste biomass (Manihot sculenta Cranz), Water Research, vol. 37, No.20, pp49134923.

Horsfall M. Jr., Spiff A. I. andAbia A. A. (2004); Studies on the influence of Mercaptoacetic acid (MAA) modification of cassava (Manihot sculenta Cranz), Waste biomass on the absorption of $\mathrm{Cu}^{2+}$ and $\mathrm{Cd}^{2+}$ from aqueous solution. Bull Korean chem.. Soc. Vol. 25, No. 6.
Insitute of Research, CSIR. Africa Technology Forum.

Kirk Othmer (1967) Encyclopedia of chemical technology, vol.2, third edition pp.112-121.

Lawal Dimeji (1994). Production of Activated Carbon from carbonaceous Materials. Unpublished Research Work, University of Lagos, Nigeria.

Nwokoma, D. B., Anene, U. (2010) Adsorption of Crude Oil using Meshed Groundnut Husks, Chemical Product and Process Modeling, Article 9, vol.5, issue 1,pp 1-21.

Olafe, O. Bosch, H. (1996). The Production of Activated Carbon from tropic carbonaceous materials. International Conference of the Nigerians Society of Chemical Engineers, pp.128-136.

Okafor, J. O., Aneke, N. A. G. (2006) Characterization of Adsorbents for the Purification of Coca-Cola Effluent, Journal of the Nigerian Society of Chemical Engineers, vol. 21, no.1\&2, pp 19-24.

Perry, R.H.: Green, D. (1997) Chemical Engineers Handbook, $7^{\text {th }}$ edition, McGraw-Hill Book Company, Newyork.

Salinas, C.: Martinez: Delecea (1981). Development of Porosity and Surface Heterogeneity upon air activation of Graphilized Carbon Black. Carbon Vol.19, pp.65-70.

Tchobanoglous, G., Burton, F. L., Stensel, D. H. (2003) Wastewater Engineering Treatment and Reuse, $4^{\text {th }}$ Edition, Tata McGraw-Hill Publishing Company Ltd, Newyork, pp 1154-1155.

Webber, J.W. Vernana, L. Snoeyink (1967). The Surface Chemistry of active carbon. Environmental Science and Technology, Vol.1 p.376 